Maja Zovko

Universidad de Zadar

\title{
Antes de la manzana: el concepto del tiempo en Voces de mujer de Lourdez Ortiz
}

Palabras clave: reinterpretación de mitos clásicos, literatura española contemporánea, concepto del tiempo

\section{Los mitos y su reescritura}

En el artículo titulado «La palabra permanente del mito y su reescritura a través del tiempo», Herrero Cecilia y Morales Peco exponen una definición del mito según la cual éste presenta una narración cuya historia «ejemplar» ha ocurrido en el «tiempo de los orígenes» o en un pasado remoto, y cuyo significado remite a lo eterno humano y se sitúa por encima del tiempo histórico. Esta definición contiene dos rasgos fundamentales del mito: su «ejemplaridad» y su dimensión atemporal que les hacen repetibles y adaptables a nuevos contextos y situaciones (Herrero Cecilia, Morales Peco, 2008). Esto ha dado lugar a que los relatos ancestrales hayan sido sometidos a lo largo de la historia a las continuas actualizaciones y elaboraciones artísticas que incluyen revisiones de su complejidad simbólica y decodificaciones de su mensaje original. Las conductas paradigmáticas, las idiosincrasias arquetípicas y las grandes hazañas de los héroes de antaño no han dejado de suscitar el interés de los escritores, que en sus textos han ido ofreciendo una visión particular de los mitos y sus personajes, de acuerdo con la cosmovisión de su tiempo y su personal punto de vista.

Si nos remontamos a los tiempos de la Grecia antigua y echamos una ojeada a los clásicos, se nos revela una concepción del hombre según la cual éste se halla supeditado a fuerzas divinas que están por encima de él. Los personajes míticos piensan, actúan, sueñan e imaginan no por sí mismos, sino por el 
influjo de las deidades, que deciden de antemano por dónde van a transcurrir los acontecimientos. Eso quiere decir que el flujo vital o psique tiene su origen en la divinidad; y que precisamente por eso los procesos mentales vienen a ser un espejo pasivo que refleja la voluntad de las fuerzas divinas subyacentes. Sin embargo, con los cambios de las sociedades europeas y con el desarrollo del pensamiento crítico, se empezó a otorgar más autonomía al hombre y a poner más énfasis en su capacidad de razonamiento ( $c f$. Asensi Pérez, 2003: 524). Análogamente, en la literatura se inicia una revisión de la herencia clásica y religiosa que culmina, en cuanto al alejamiento del argumento y enfoque original, en el siglo veinte con la publicación de numerosas obras literarias que ofrecen una versión subvertida de grandes historias de nuestra memoria colectiva.

La colección de relatos Voces de mujer (2007) ${ }^{1}$ de Lourdes Ortiz es un ejemplo ilustrativo de la recreación del mito a la luz del diálogo personal de la autora con las historias pertenecientes a la Biblia y la mitología clásica y su ruptura con la tradicional visión de los personajes femeninos como Eva, Circe, Penélope, Betsabé y Saloméz. A partir del argumento contado en los textos antiguos, Lourdes Ortiz construye un nuevo discurso literario distorsionando en mayor o menor medida la historia original con la intención de desentrañar, desde una perspectiva femenina, el interior de sus personajes y cuestionar una serie de estereotipos que se asocian a ellos.

Por el tratamiento de sus protagonistas, al igual que su novela Urraca, esta colección de relatos fue tachada de feminista a lo que la autora se pronunció puntualizando que ella no se lo había planteado al escribirlos (Pulido, 1997). También hubo palabras de elogio, aunque expresadas con cierta reserva: «Lourdes Ortiz es una narradora que, en cada libro, enriquece su técnica y la extensión del mundo. Los motivos de Circe pudiera considerarse un libro menor, de no ser porque alcanza la summa de la capacidad poética de la autora» (Sin nombre, 1998). Y efectivamente, la carga lírica y la fuerza sugestiva de las imágenes poéticas que crea la escritora así como la originalidad del punto de vista de los personajes, despojados de todo tipo de prejuicios y esquematismos, constituyen un auténtico aliciente para el lector.

1 Los relatos pertenecientes a esta colección fueron reunidos por primera vez en 1988, luego reeditados bajo el título de Los motivos de Circe en 1991.

2 Esta colección incluye también un cuento dedicado al personaje de Gioconda. Por no tratarse de un personaje de la mitología griega o la Biblia, no será analizado en este estudio. 


\section{La técnica narrativa y el concepto del tiempo}

Los relatos que forman parte de Las voces de mujer se diferencian entre sí en cuanto a la elección del personaje femenino retratado y la proyección que éste ha tenido en la literatura. Distan mucho la prudente Penélope, fiel y sumisa esposa del héroe de Ítaca, la primera pecadora Eva, Circe, maga griega de las lindas trenzas, o las transgresoras como Salomé o Betsabé. Sin embargo, los procesos psicológicos de todos estos personajes, sumergidos, sin excepción, en una gran soledad, difieren mínimamente. Por eso no extraña que Lourdes Ortiz acuda a los mismos procedimientos literarios para reflejar los recovecos del alma de estas grandes figuras femeninas.

La voz narradora se sitúa en la mente de estas cinco protagonistas en los momentos de reencuentro consigo mismas y con el pasado que marcó sus vidas. A diferencia de sus representaciones clásicas o religiosas, estas mujeres ofrecen ahora su propia versión del mito, cuestionan su pasado y su condición de mujer. Los cuentos están constituidos a base de monólogos interiores indirectos que expresan los pensamientos más íntimos de los personajes, próximos al subconsciente, antes de toda organización lógica. En concordancia con la tesis de que los monólogos interiores «asocian acontecimientos pretéritos a una experiencia presente» (Anderson Imbert, 1991: 78), las protagonistas de estos cuentos exponen su interior desde un ahora, y lo trasladan a un momento del pasado crucial para el entendimiento de su modo de ser.

Las reminiscencias de los sucesos pasados no sirven para vislumbrar una acción presente, sino el estado y la evolución psicológica de estos personajes. El uso del monólogo interior condiciona la estructura de estos relatos en los que no faltan frases inacabadas, puntos suspensivos, distorsiones sintácticas, exclamaciones, interrogaciones y también la inevitable deformación temporal, ya que «la denominada literatura del «monólogo interior» se limita a la reproducción de los «contenidos de la conciencia», y, por lo tanto, no está sujeta a ningún análisis cronológico» (Bal, 2009: 64). Se trata de un procedimiento narrativo que los autores utilizan, en la mayor parte de las veces, con ciertos fines estéticos (Todorov, 2006: 179). Y en el caso de Lourdes Ortiz sirve para sugerir e intensificar la intimidad de los personajes, aumentar la tensión producida por la represión de sus deseos y sus temores que, por fin, a través de este fluir de la conciencia, brotan al exterior y se apoderan del discurso narrativo. 


\section{Antes de la manzana}

Además de las peculiaridades en el tratamiento narrativo de la dimensión temporal por parte de Lourdes Ortiz, la noción del tiempo juega un papel primordial en Las voces de mujer. Es muy significativo que el cuento que abre la colección, «Eva», consta de veintisiete breves párrafos de los cuales cinco incluyen en su primera frase el adverbio «ahora», tres el adverbio «entonces», cuatro expresiones adverbiales de tiempo como «aquella noche / aquella tarde», tres la palabra «tiempo». El párrafo número catorce contiene la frase inacabada: «Antes de la manzana», que encierra el mensaje clave del relato: el de la desigualdad genérica (Ortiz, 2007: 933). Esta frase marca la línea divisoria entre la felicidad del paraíso, un lugar sin límites temporales, y el primer pecado que conlleva la expulsión del Edén. Eva rememora que a partir de aquel momento por primera vez nace el adverbio, «un más allá, un lejos, un fuera» (89).

El tiempo se convierte en uno de los pensamientos centrales de Eva que define la época previa a la manzana como el período en que el tiempo no existía:

El tiempo, piensas, y al decirlo vuelves a experimentar un escalofrío, pero no por el viento, ni por la humedad, ni por la lluvia, sino por el terror, porque sabes que fue también en aquel preciso momento cuando el tiempo se hizo denso y pesado, como una sucesión, como un avecinarse, prolongarse, era algo que se podía medir, casi cortar... [...] ... pero prefieres que no se mezclen las acciones, ni los recuerdos, precisamente porque ahora, desde aquel momento, existe el tiempo delimitado, hay antes y hay después y Caín entonces todavia. (91)

Con el destierro, se despierta en Adán - hasta entonces «parte indiscernible de ella misma» (88) - el afán por ganar bienes materiales, manifestado con la adquisición de la piel de leopardo. Es justamente este episodio el que hace de Eva una mujer sumisa y agradecida y que supone un antes y un después en su relación de pareja. Eva toma conciencia de su nueva posición frente al compañero, «ya no parte de su cuerpo, ya no piel de su piel» (92), a diferencia de los tiempos antes de la culpa.

A lo largo del cuento nos encontramos con una sucesión de las reminiscencias de Eva y sus pensamientos situados en el presente, ya después de la muerte

3 Todas las citas provenientes de esta colección de cuentos serán indicadas solamente con el número de página 
de Abel. La amplitud de la distancia temporal de los días felices en el paraíso terrenal va reforzada por los demostrativos, como se observa en los siguientes ejemplos: «aquella tristeza», «aquel fulgor», «aquella primera vez», «en aquel preciso momento», «a partir de ese instante», «desde aquel día», «aquella tarde». La historia avanza, con sucesivos cambios de tiempos verbales y saltos del presente al pasado, en una analepsis acelerada a través de numerosas elipsis internas y también desacelerada con las pausas que hacen hincapié en el aspecto durativo de los estados melancólicos y la frustración interior del personaje de Eva, estados que se resaltan con las repeticiones del adverbio temporal «mientras». Se proyecta una imagen solitaria y triste de Eva que cierra reiteradamente los ojos para soñar con el amor original cuando «el tiempo se anulaba y se perdían los límites» (96) y el hombre y la mujer estaban unidos por la palabra y por la igualdad.

Sin embargo, el tiempo se perpetúa en los hijos que heredan las características de sus progenitores de manera que se convierten en las encarnaciones del modelo femenino y masculino, siendo Abel la prolongación de Eva «machohembra que asumía la síntesis de aquella primitiva unión, antes de nuevo de la manzana» (95).

El relato tiene una estructura cíclica, ya que termina con las alusiones de Eva a aquellos patos paradisíacos mencionados al inicio de la narración, a los que Adán no sabía poner nombre ni clasificar, «aquellos patos del principio, cuando el verbo era verbo, antes de la manzana» (100).

\section{Pero siempre es lo mismo: la batalla contra el tiempo de la eterna maga dotada de voz}

Si en el cuento «Eva» se insistía en el punto de inflexión expresado con la frase «antes de la manzana», en «Los motivos de Circe», se hace hincapié en el aspecto monótono y reiterativo de la vida de la protagonista a través de la repetición: «pero siempre es lo mismo».

El presente del discurso narrativo se sitúa en una isla en medio del Mediterráneo, en la que Circe rememora un lapso temporal concreto y limitado, un año del amor que pasó junto a Ulises y durante el cual no consiguió retenerle a su lado, ya que Ulises «prefirió la soledad, el miedo, el tiempo, el límite, la acción y la muerte» (117). La maga dotada de voz no pudo convencerle entonces de que «aquel era el tiempo verdadero, el no-tiempo, el lugar del goce» (118). Las evocaciones del pasado se bifurcan. Por un lado tenemos el pasado de aquel año 
de amor y por el otro, el pasado aún más remoto que no está contado a través de una voz omnisciente situada en la memoria de Circe, sino a través de las conversaciones desarrolladas durante ese año, cuando Ulises, «ya no navegante y un viajero infatigable, era poeta y narrador, que contaba y recontaba cada una de su hazañas adornando su narración con pequeños matices, como si sus sentidos fueran despertando al placer del cuento inacabado, del relato imperecedero» (110). Su cuidado por la pausa, el adjetivo y la progresiva y medida descripción de los distintos movimientos lo hacen no sólo rico en ardides, sino también un diestro narrador, que sabía detener la narración o acelerar de pronto el ritmo. Las constantes y repetidas alusiones al acto de contar de Ulises, con las que se insiste en la duración de los diálogos de la pareja, por ejemplo, él hablaba y hablaba (110), una y otra vez jugaba con los ritmos, con las pausas (113), contar y contar (115), son utilizadas para acentuar, por un lado, el vínculo afectivo de Circe hacia Ulises y, por el otro, el carácter egocéntrico del héroe que se imponía en la relación de pareja ya que siempre existía un Yo enorme (114).

Además de estas analepsis mediante las cuales se hace referencia a los momentos tanto de la vida de Ulises como los del año que pasó en la isla de Circe, en el relato encontramos anticipaciones repetitivas. Los pensamientos exteriorizados de la hechicera van dirigidos a los hombres que llegan a su isla:

Les ve bajar de las naves a los marineros, tambaleándose aún, conservando en las piernas el suave ondular de las olas [...] y no hablarán, ni siquiera se detendrán a contemplar la sabia construcción de la piedra [...]. Y así será una vez más sin que ella, Circe, pueda hacer nada por impedirlo, aunque añore la compañía y, cuerpo de varón: unos se convertirán en leones que rondarán el palacio dóciles como gatitos [...]. (102-105)

En el presente narrativo, Circe desde su palacio contempla la insondable soledad azul del mar mientras que la eternidad que le corresponde como diosa pesa sobre sus sentimientos de mujer abandonada. Circe, que deseaba haber tenido una flor de loto para que Ulises se fuera olvidando de aquella patria lejana, no pudo combatir el tiempo ni hacer nada por cambiar su flujo. Este cuento también tiene una estructura circular. Termina con la misma frase elíptica con la que se abre: «como cerdos...» y con la misma imagen de Circe, que ya no es la maga dotada de voz, sino la de un «canto amargo de nostalgias y de amores que ya nunca serán» (119). 


\section{La inútil espera de Penélope}

En el siguiente cuento, la monotonía predominante en «Los motivos de Circe», se cambia por la frustrada espera de Penélope durante el lapso temporal de veinte años. La narración condensa los días previos a la llegada de Ulises así como el encuentro de Penélope con su anciano esposo después de su larga ausencia. La hija de Icario, con el cuerpo venciéndose, lamenta su perdida batalla contra el tiempo refugiándose en el tejer de «una tela inacabable de deseos insatisfechos», «un sudario de la propia carne» (122-123) y recordando los cuentos del incansable narrador, «aquel diestro en embustes que rompió su doncellez y le hizo un hijo, ese hijo que ahora crece, como imagen del padre, frente a ella y que vuelve a recordarle una y otra vez quién es el amo» (123).

El interés por la dimensión temporal del relato va enfocado en el deseo de la protagonista de resistir al transcurso del tiempo. La autora yuxtapone la risa argentina de Circe y los gritos de las jóvenes y desvergonzadas esclavas que se divierten con los pretendientes con la imagen de una Penélope arrugada, con el cuerpo vencido por la larga espera, dedicada al tejido «rechinante del tiempo» (126). Una Penélope que sueña con el que «se mantiene intacto con el paso del tiempo, divinal y joven para ella» (127). Al igual que en el anterior relato, la soledad de la protagonista viene aumentada con referencias temporales como «veinte años permitiendo que Atenea [...] ponga a sus ojos un plácido sueño» (122), «veinte años que ella cuenta los metros de hilo» (126), «de tarde en tarde» (125) o día tras día [...] siempre altiva (125). El ritmo reiterativo de la narración se interrumpe con la llegada de Ulises y la frase que supone el cambio del tono narrativo: «Veinte años esperando y ahora aquel anciano...» (133). En la Odisea también se muestra una preocupación por el envejecimiento, resuelto gracias a la magia de Atenea que derramó sobre la cabeza de Ulises abundante gracia para que pareciera más alto y más ancho e hizo que cayeran de su cabeza ensortijados cabellos semejantes a la flor del jacinto (Homero, 2009: 375). Sin embargo, el texto original y su reflejo literario en el siglo veinte ofrecen una imagen final muy distinta de Penélope. Homero insiste en la ejemplaridad conyugal de la fiel esposa de Ítaca cuya fama de su virtud «no perecerá y los inmortales fabricarán un canto a los terrenos hombres en honor de la prudente Penélope» (Homero, 2009: 388). Y Lourdes Ortiz, por su parte, centra la última parte de la narración en la prudente e irreprochable Penélope en aquella cama de olivo que contempla a Ulises y llora por el tiempo perdido y los largos años de inútil espera, ya que «Él tiene tras sí una historia para narrar, y ante él una hacienda que reconstruir y que legará a su hijo. Ella, la esposa, que ya no está en edad de volver a ser madre y renunció, cuando era tiempo, al tacto de los 
cuerpos jóvenes» (134). Al igual que los anteriores personajes, Penélope también se refugia en el sueño y deja que los fantasmas de pretendientes le devuelvan el eco de un goce que ya no puede ser (135).

\section{Betsabé y Salomé: reminiscencias de una transgresión}

El cuento «Betsabé» se abre con un presente narrativo que resalta la plenitud del momento de la protagonista expresada con la frase «Ahora se han cumplido los días». La esposa del rey David, tranquila y victoriosa, escucha y observa a lo lejos la ceremonia de la coronación de su hijo Salomón. Los campos resecos, las higueras que exhalan una fragancia espesa y rancia, la melisa de leche recalentada y el perfume intenso de la mirra, no sólo constituyen bellas imágenes cargadas de lirismo, sino que también aluden a la madurez de la protagonista y al inevitable paso del tiempo que «se coagula y se hace obsceno entre las canas y en los surcos agrietados de una frente recubierta por un maquillaje rancio» (139).

La satisfacción de Betsabé se potencia en el tercer párrafo cuya frase inicial una vez más alude a la mesurada felicidad de la protagonista en el momento presente, «Hay un llamear de antorchas en el horizonte y la mujer sonríe», para intensificar unas líneas más abajo esta sensación de felicidad de la de Betsabé que ríe, como si Lilith, «la vieja madre adúltera de todos los seres infernales riera a través de aquellos labios» (140). Paralelamente, desde la habitación de al lado llegan «las quejas de anciano que se rebulle en el lecho luchando inútilmente por insuflar una virilidad perdida a un cuerpo gastado también por el tiempo». A diferencia de Betsabé, el decrépito rey ya ha perdido la batalla contra el tiempo intentando recuperar algo de su perdida hombría con una joven sunamita enviada por la misma Betsabé.

Son significativas tres acciones simultáneas situadas en el presente: la coronación de Salomón, el descanso de Betsabé en la azotea, y el encuentro del viejo rey con la sunamita. Betsabé es el primer personaje femenino de la colección que no vive anclado en el pasado, pasivo frente al transcurso del tiempo, sino que ha tomado el mando de su propia vida, aunque utilizando sin escrúpulos todo tipo de artimañas. «Encadenados los pensamientos de Betsabé cabalgan atravesando el tiempo» (143) y sacan de la memoria los episodios como el de la violación de Tamar por parte de su hermano Amnón, asesinado a manos de Absalón, al que había incitado a que se acostara con las diez concubinas preferidas de su padre, cuyo artífice en esta versión de la historia 
bíblica es la misma Betsabé. La insistencia en el presente, vivido de manera muy intensa por parte de la protagonista a través de estas acciones paralelas, es la manera de acentuar la imagen de una Betsabé realizada.

Al igual que en «Eva», en este cuento también los mecanismos analépticos están vinculados con un acontecimiento pasado que supone un viraje en la historia y al que el narrador se refiere repetidamente con los indicadores temporales como: «aquel entonces», «aquel primer momento, el de la herida», «el momento del baño». Muchas lunas, se insiste en el texto, han pasado desde que el rey se percató de una entonces jovencísima Betsabé mientras se bañaba en su azotea y decidió tomarla por su esposa, después de haber enviado a su marido, el soldado hitita, a la primera línea del frente. La presente imagen de una Betsabé poderosa contrasta con quien ella fue en tiempos de guerra, una «mujer sin varón y a la espera», al igual que Penélope (141).

La sucesión de los hechos posteriores al encuentro con el rey desembocaron en «años de desamor y de derrota, de impureza y de deseo volcado hacia ese hijo que hoy [...] borra por fin la mancha» (142). Se establece un paralelismo entre el presente y el pasado, entre la frustración del viejo y debilitado David con la muchacha sunamita y el frío que en otros tiempos sintió la joven Betsabé ante la avarienta mirada del monarca, condenada a «un destino no querido y a una apuesta por un futuro que sólo podría realizarse en el hijo» (142). La autora, nuevamente, acude a la circularidad del relato, cerrando la narración con el triunfo del hijo, la serenidad de Betsabé y la vejez del rey.

La versión del personaje bíblico de Salomé de Lourdes Ortiz tiene su inspiración en la obra dramática de Oscar Wilde en la que Salomé, ya no manipulada por su madre, sino motivada por la indiferencia del profeta san Juan hacia ella, provoca su muerte para satisfacer su deseo y quedarse con sus ojos. Este motivo aparece también en el relato de Lourdes Ortiz diferenciándose en el impulso de las protagonistas para causar la muerte del profeta. La voz narradora de Salomé va desvelando, a través de una analepsis, los hechos pasados desde un presente que compone la imagen de Salomé frente a los ojos de San Juan. Esta vez el antes y después supone el encuentro de la hetaira con el profeta cuyos ojos, «aquella luz» (162), por primera vez, le despojaron de la ira y del deseo y la hacía igual a él (160-162). Los pensamientos de la narradora además de situarse en este hecho que define como un relámpago (160) y un bautismo que le devolvía la sabiduría (163) y que ella describe como catártico, se refieren a su educación recibida en el harén de las mujeres, absorbida desde el comienzo por las acechanzas y los consejos de su madre (162). La duración y reiteración de este pasado anterior 
al de la iluminación a través de la mirada de San Juan Bautista, expresadas a través de la insistencia de Salomé de repetir una y otra vez el vaivén de la cadera, sabiamente estudiado (162), contrastan con la instantaneidad de la luz recta de la mirada del profeta que le «devolvió por un instante la verticalidad del ser, la seguridad del relámpago» (164) y que la convirtió en «luz que atraviesa los confines del tiempo y del espacio, Sofía encarnada» (168). El relato termina con la escena de Salomé, que desde hace tres noches y tres días permanece muda, ante los ojos que le obsequian con la sabiduría.

\section{Conclusiones}

En todos estos relatos, observamos que el tiempo se presenta como el mayor enemigo de las protagonistas. El tiempo nacido a partir de la manzana, supone los límites y la subordinación de Eva que no logra combatirlo ni siquiera a través de su maternidad, ya que su hijo predilecto, el que encarna el modelo femenino, muere a manos de su hermano. La eternidad concedida a la divina Circe no le ayuda a sobreponerse a Ulises y la poderosa hechicera se reduce a un sujeto pasivo, capaz únicamente de refugiarse en los recuerdos de un año que le unió al gran guerrero homérico. Penélope, por su parte, no se realiza en la maternidad, pues su hijo repite el esquema patriarcal del hombre dominante tanto en la sociedad como en su propio hogar. La autora acaba con la imagen idealizada de la fiel y paciente esposa, ya que Penélope «sierva del hijo [fue] como sierva del padre» (133) se desmorona ante el paso del tiempo y se arrepiente por haberse marchitado durante esos veinte años de inútil espera. La única que ha vencido el tiempo es Betsabé. Los terrores y odios acumulados a lo largo de su vida junto al rey David tienen su fin con el entronamiento de Salomón. A través de la maternidad es la única que aparentemente ha ganado la batalla al tiempo y también la batalla contra la desigualdad sexual, pero tampoco mediante su propia realización personal, sino gracias a numerosas especulaciones y a su hijo, nacido para borrar la mancha familiar y para anular el crimen. El relato «Salomé» está centrado en el instante catártico del encuentro de la protagonista con San Juan, que desencadena el enlace fatídico de la muerte del profeta.

Volviendo a la relación entre los mitos, la literatura y el tiempo, nos remetimos a las palabras de Carlos García Gual:

El mito narra un acontecimiento, cuyo origen le trasciende, del que se encuentra ya alejado o distanciado fatalmente en el tiempo, pero el relato le permite preservar la memoria de un 
origen y alentar hacia su re-iteración, -el nuevo comienzo- en la esperanza (García Gual, 1998: 51).

Las continuas revisiones de los mitos clásicos y religiosos les conceden vitalidad y dimensión humana, suscitando nuevamente interés por su recreación. Eva, Circe, Penélope, Betsabé y Salomé, ya no arquetipos, sino complejos personajes femeninos con sus propias señas de identidad muestran que, al menos en el campo de la literatura, han sabido resistir al tiempo desafiando su flujo y dispuestas a poner fin a la imagen tradicional proyectada sobre ellas.

\section{Bibliografía}

Aguirre, F. (1972): Itaca. Madrid: Cultura Hispánica.

Anderson Imbert, E. (1991): Teoría y crítica del cuento. Barcelona: Ariel.

Andrés Argente, J. de (2003): Lourdes Ortiz. Madrid: Ediciones del Orto.

Asensi Pérez, M. (2003): Historia de la teoría de la literatura, II. Valencia: Ediciones Marymar.

Bal, M. (2009): Teoría de la narrativa (una introducción a la narratología). Madrid: Cátedra.

Beauvoir, S. de (2002): El segundo sexo, I: Los hechos y los mitos. Madrid: Cátedra. Boitani, P. (2001): La sombra de Ulises. Imágenes de un mito en la literatura occidental. Barcelona: Península.

Buero Vallejo, A. (2005): La tejedora de sueños. Madrid: Cátedra.

Cixous, H. (2001): La risa de la medusa. Ensayos sobre la escritura. Madrid: Anthropos.

Cristóbal, V. (2000): «Mitología clásica en la literatura española: consideraciones generales y bibliografía». En: Cuadernos Filológicos Clásicos. Estudios Latinos, $18,29-76$.

Díez del Corral, L. (1974): La función del mito clásico en la literatura contemporánea, Madrid: Gredos.

Esposti, B. degli (1998): El enigma de lo femenino: Eva, Orlando, Madame Bovary. Madrid: Grupo Cero.

García Gual, C. (1996): Mitos, viajes, héroes. Madrid: Taurus.

García Gual, C. (1998): «Mito, historia y razón en Grecia: Del mito al logos».

En: Carlos García Gual et al., Nuevo romanticismo: la actualidad del mito. Madrid: Fundación Juan March, 19-33. 
Gentile, B. (2008): L'altra Penélope. Salerno-Milano: Oèdipus.

Giralt, L. (2001): Innovaciones y tradiciones en la novelística de Lourdes Ortiz. Madrid: Pliegos.

González Ovies, A. (2003): «Mitos de ayer y poesía contemporánea». En: Rosa María Cid López, Marta González González (eds.), Mitos femeninos de la cultura clásica: creación y recreación en la bistoria y la literatura. Oviedo: KRK, 99-22.

Herrero Cecilia, J., Morales Peco, M. (2008): «La palabra permanente del mito y su reescritura a través del tiempo». En: Juan Herrero Cecilia, Montserrat Morales Peco (coords.), Reescritura de los mitos en la literatura: estudios de mitocrítica $y$ de literatura comparada. Cuenca: Universidad Castilla-La Mancha, 13-27.

Homero (2009): Odisea. Madrid: Cátedra.

Mossé, C. (2001): La mujer en la Grecia clásica. Hondarribia: Nerea.

Ortiz, L. (2007): Voces de mujer. Madrid-Fráncfort del Meno: IberoamericanaVervuert.

Pulido, N. (1997): «Las autoras se lamentan de que todavía no se las tome en serio en la literatura». En: $A B C, 31$ de agosto de 1997, 51.

Romero Yebra, A. Ma. (1998): El llanto de Penélope. Madrid: Torremozas.

Sin nombre del autor (1998): «Los motivos de Circe. Lourdes Ortiz». En: $A B C, 1$ de octubre de 1998, 66.

Todorov T. (2006): «Las categorías del relato literario». En: VV.AA., Análisis estructural del relato. México: Ediciones Coyoacán, 161-197.

Ureña Bracero, J. (2002): «Mujer y discriminación en la sociedad griega. Tragedia». En: Santiago López Moreda (ed.), Contemporaneidad de los mitos clásicos. Madrid: Ediciones Clásicas, 59-67.

VV.AA. (1998): Nuevo romanticismo: la actualidad del mito. Madrid: Fundación Juan March.

VV.AA. (2006): Análisis estructural del relato. México: Ediciones Coyoacán.

Vega, L. de (2003): «La Circe». En: Obras completas. Poesía, IV. Madrid: Biblioteca Castro.

Vías Mahou, B. (2000): La imagen de la mujer en la literatura occidental. Madrid: Anaya.

Wilde, O. (2005): Salomé. Barcelona: Galaxia Gutenberg. 
Maja Zovko

University of Zadar

\section{Before the apple: the concept of time in Voces de mujer of Lourdes Ortiz}

Keywords: reinterpretation of classical myths, Spanish contemporary literature, concept of time

The collection of stories by Spanish contemporary writer Lourdes Ortiz, Voices of Women, first published in 1991 under the title The reasons of Circe and republished in 2007 (Iberoamericana-Vervuert), is dedicated to the great female characters of Greek mythology and the Judeo-Christian tradition. The author's purpose is to revise and subvert the ancient stories from the original plot of the Odyssey and the Old Testament, as well as to strip the protagonists (Eve, Penelope, Circe, Salome and Bathsheba) of the stereotypical image that has been attributed to them in previous centuries.

By means of carefully premeditated language full of lyricism, Lourdes Ortiz successfully potrays the psychology of her characters, using a short original plot, enriched and intensified with a series of beautiful and suggestive images, complex metaphors and carefully chosen verb tenses.

This study aims to investigate the concept of time in the collection Voices of Women of Lourdes Ortiz, challenging the linearity of the narrative, the cyclical and parallel constructions, the distribution of tenses and time references, which were elaborated according to the main objective of the author: to unravel the complex ancestral figures and thus provide a humane vision of the great stories of our collective memory. 
Maja Zovko

Univerza v Zadru

\section{Čas pred jabolkom: Voces de mujer Lourdes Ortiz in pojem časa}

Ključne besede: ponovna interpretacija klasičnih mitov, sodobna španska književnost, pojem časa

Zbirka kratke proze Lourdes Ortiz Voces de mujer (Ženski glasovi), ki je bila prvič objavljena z naslovom Los motivos de Circe (Motivi Kirke) in nato ponovno leta 2007 pri založbi Iberoamericana-Vervuert, je posvečena velikim ženskim likom iz grške mitologije in judovsko-krščanske tradicije. Pisateljica izhaja iz Odiseje in Svetega pisma ter na novo interpretira in spreminja starodavne zgodbe tako, da junakinjam, kot so Eva, Kirka, Saloma, Penelopa in Batšeba, odvzema skozi stoletja dodeljeno stereotipno podobo.

Lourdes Ortiz je uspelo posredovati psihološke značilnosti svojih junakinj z lirično obarvanim in skrbno izbranim jezikom, kratkimi vsebinskimi povzetki, ki so intenzivno olepšani, zahvaljujoč nizu čudovitih sugestivnih podob in večplastni uporabi metafor, ter s skrbno izbranimi glagolskimi časi.

Članek skuša raziskati pojem časa v kratki prozi Lourdes Ortiz, in sicer gre za prekinjanje linearnosti, vzporedne in ciklične konstrukcije, porazdelitev glagolskih časov ter za kronološke reference. Časovnost avtorici služi v podporo osnovnemu cilju, tj. dognati notranjost starodavnih večplastnih likov in tako ponuditi počlovečeno podobo velikih zgodb, ki predstavljajo del našega skupnega spomina. 